\title{
Carbonation Behavior of Fly Ash with Circulating Fluidized Bed Combustion (CFBC)
}

\author{
Soon Jong Bae and Ki Gang Lee ${ }^{\dagger}$ \\ Department of Advanced Materials Science and Engineering, Kyonggi University, Suwon 443-760, Korea
}

(Received January 7, 2015; Accepted February 11, 2015)

\begin{abstract}
This paper investigates the reaction rates of $\mathrm{CO}_{2}$ that stores carbonation through comparing the carbonation behavior between $\mathrm{Ca}(\mathrm{OH})_{2}$ and fly ash with circulating fluidized bed combustion (CFBC) containing a large amount of free CaO. Because fly ash with CFBC contains abundant free $\mathrm{CaO}$, it cannot be used as a raw material for concrete admixtures; hence, its usage is limited. Thus, it has been buried until now. In order to consider its reuse, we conduct carbonation reactions and investigate its rates. X-ray diffraction (XRD), thermogravimetric/differential thermal analysis (TG/DTA), and X-ray fluorescence (XRF) are conducted for the physical and chemical analyses of the raw materials. Furthermore, we use a $\mathrm{PH}$ meter and thermometer to verify the carbonization rates. We set the content of the fly ash of $\mathrm{CFBC}, \mathrm{Ca}(\mathrm{OH})_{2}, \mathrm{CO}_{2}$ flow rate, and water to $100 \sim 400 \mathrm{~g}, 30 \sim 120 \mathrm{~g}, 700 \mathrm{cc} / \mathrm{min}$, and $300 \sim 1200 \mathrm{~g}$, respectively, based on the content of the free $\mathrm{CaO}$ determined through the TG/DTA analyses. As a result, the carbonization rate of the fly ash with CFBC is the same as that of $\mathrm{Ca}(\mathrm{OH})_{2}$, and it tends to increase linearly. Based on these results, we investigate the carbonization behavior as a function of the free $\mathrm{CaO}$ content contained in the raw material.
\end{abstract}

Key words : Carbonation, Fly ash, $\mathrm{CFBC}, \mathrm{Ca}(\mathrm{OH})_{2}, \mathrm{CO}_{2}$

\section{Introduction}

$\mathrm{C}$ ombustion methods to produce energy at thermal power plants by using coals include powdered coal combustion method and fluidized bed combustion method, and a fluidized bed boiler is an apparatus to efficiently burn low-grade (low calorific value) bituminous coals. Also, the circulating fluidized boilers are used for the reason of minimizing NOx generation, since the fluidized bed boilers having a long combustion time for bituminous coals can desulfurize within the furnace and the combustion temperature is low while the existing desulfurization equipment are very expensive. In the case of fluidized bed combustion method, however, Free-CaO component which failed to participate in hydration reaction of concrete when used as a concrete admixture induces fatal problems in terms of durability, expansion, weathering, cracking, etc. of concrete ending up with total landfill without being recycled, as the $\mathrm{CaO}$ compound compostion is contained in fly ash by a large quantity due to in-furnace desulfurization and the $\mathrm{SiO}_{2}$ content fails to comply with the KS specification (KS L 5405). Thus, many studies are being carried out to stabilize Free-CaO, because of advantages that $\mathrm{CO}_{2}$ can be stored permanently in a stable manner when carbonate mineralization processes are applied. ${ }^{1,2}$

\footnotetext{
${ }^{\dagger}$ Corresponding author : Ki Gang Lee

E-mail : gglee@kyunggi.ac.kr

Tel : +82-31-249-9762 Fax : +82-31-244-6300
}

Domestically, Byeon et al. ${ }^{3)}$ have demonstrated a carbonation implementation process of the raw material through carbonation by using steelmaking slags as an industrial byproduct, while Ahn et $a l .{ }^{4)}$ have stated that an accelerated carbonation technique is applicable as a technique for reduction of carbon dioxide through wet carbonation reaction of waste concrete fine powders. In addition, Kim et al. ${ }^{5,6)}$ have tried to solve expansion problems through stabilization by carbonating the Free-CaO component of steelmaking slags and solve expansion of concrete by adding water glass to concrete using steelmaking slags in Korean registered patent(10-0538586, 10-0592870). Also, for studies on carbonation reaction rates, Lee et $a l .{ }^{7)}$ conducted experiments for determining feasibility of carbonation by using fluidized bed fly ash, while Ahn et al. ${ }^{8)}$ have obtained the results that reaction rates were linearly increased with an increase in solid content and temperatures as a result of checking reaction rates by preparing suspension with $\mathrm{Ca}(\mathrm{OH})_{2}$ as a raw material and conducting carbonation experiments, and Jo et al. ${ }^{9)}$ conducted wet carbonation experiments by using fly ash and affirmed reserves according to $\mathrm{CaO}$ contents from the result that reaction rates were similarly linear. However, studies on carbonation behavior and recycling of fluidized bed fly ash are very inadequate and recycling of the fluidized bed fly ash is very limited since no studies on carbonation of a large content of fluidized bed fly ash have been implemented.

Thus, in the present study, carbonation behavior of Free$\mathrm{CaO}$ contained in the fluidized bed fly ash by a large content was compared with that of $\mathrm{Ca}(\mathrm{OH})_{2}$ to convert a large con- 
tent of the fluidized bed fly ash into environmentally and chemically stable materials for recycling in various areas such as concrete admixture, etc., and an investigation of carbonation reaction mechanisms was attempted by measuring carbonation reaction rates and reaction temperatures as a function of solid-liquid ratios and an increase in solid contents.

\section{Experimental Procedure}

\subsection{Analysis of raw materials}

The results of analyzing chemical compositions of fluidized bed fly ash employed in the present experiment through XRF(ZSX-100e, Rigaku, Japan) are indicated in Table 1. As the major chemical compositions, $\mathrm{SiO}_{2}$ and $\mathrm{CaO}$ compositions are $24.7 \%$ and $38.35 \%$, respectively, while $\mathrm{S}$ composition is $10.15 \%$, and it can be seen that there are large contents of gypsum and Free-CaO. To check for crystalline phases of the large content of $\mathrm{CaO}$ present in fluidized bed fly ash, XRD analysis was conducted, while DTA/ TG analysis was also employed to check for the content of Free-CaO.

\subsection{Carbonation experiment of suspension of fluid-} ized bed fly ash, $\mathrm{Ca}(\mathrm{OH})_{2}$

Precipitated calcium carbonate preparation method has been employed and conducted at room temperature, where $\mathrm{CO}_{2}$ gas (99\% in purity) is injected in the suspension prepared by mixing water with fluidized bed fly ash containing a large content of $\mathrm{CaO}$ as the major composition of carbon storage. Carbonation reaction was induced by injecting $\mathrm{CO}_{2}$ gas in the suspension of fluidized bed fly ash mixed with water in a plastic beaker of $2000 \mathrm{ml}$ for container volume, and a magnetic agitator was used to dissolve the fluidized bed fly ash within the suspension properly in water. In addi-

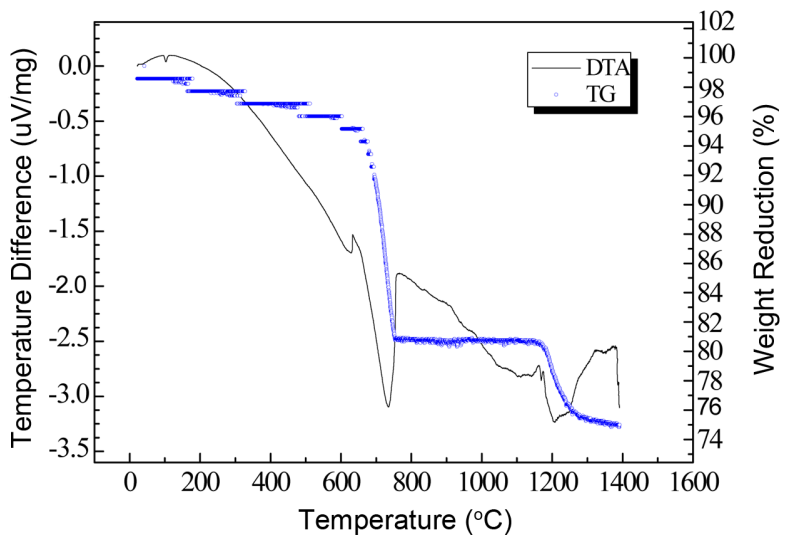

Fig. 1. TG-DTA Analysis of fly ash after carbonation reaction. tion, $\mathrm{CO}_{2}$ needs to be properly stored in the condition of aqueous solution with $\mathrm{CaO}$ component dissolved in water to check for carbonation reaction rates. For such purpose, conversion of $\mathrm{CO}_{2}$ to an ionized state becomes difficult unless there is a sufficient content of liquid in the suspension. To affirm this, an experiment was conducted after the solid content of the suspension was made to be constant, and a slid-liquid ratio was selected by determining the liquid content that could be agitated sufficiently. Carbonation was conducted under the experimental conditions where the solid-liquid ratio was $1: 3$, the $\mathrm{CO}_{2}$ flux $700 \mathrm{cc} / \mathrm{min}$ and the solid content in the fluidized bed fly ash $100 \mathrm{~g}$. Also, the experiment was conducted by using $\mathrm{Ca}(\mathrm{OH})_{2}$ for which the use of only $\mathrm{CaO}$ was allowed as the major component for carbonation reaction, excluding other raw materials included in the fluidized bed fly ash. For $\mathrm{Ca}(\mathrm{OH})_{2}$, the solid content was fixed at $30 \mathrm{~g}$, the $\mathrm{CO}_{2}$ flux at $700 \mathrm{cc} / \mathrm{min}$ with the liquid contents of $240 \mathrm{~g}, 300 \mathrm{~g}, 600 \mathrm{~g}$ (solid-liquid ratios of $1: 8,1: 10,1: 20)$, considering that $\mathrm{Ca}(\mathrm{OH})_{2}$ generation produced by reaction of the $\mathrm{CaO}$ content in the fluidized bed fly ash with water was 30\%(TG analysis result), and carbonation was performed after factors obstructing dissolution of $\mathrm{CO}_{2}$ in water were removed by allowing sufficient agitation. After progress of the carbonation reaction, changes in $\mathrm{pH}$ were checked at an interval of 2 seconds by using a $\mathrm{pH}$ meter (pH-230SD, Lutron, Taiwan), and changes in temperature were measured at an interval of 2 seconds by using a thermometer (MTM-380SD, Lutron, Taiwan) to check for temperature rises due to the exothermic reaction. In addition, generation status of $\mathrm{CaCO}_{3}$ as a carbonation product of $\mathrm{CaO}$ was checked through XRD analysis of crystalline phases.

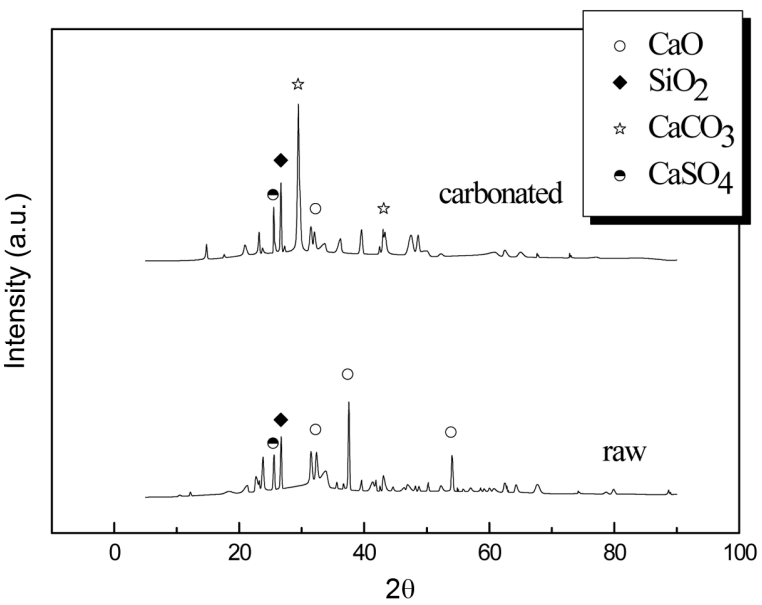

Fig. 2. XRD analysis of raw fly ash and carbonated fly ash.

Table 1. Chemical Compositions of Fly Ash(\%)

\begin{tabular}{|c|c|c|c|c|c|c|c|c|c|c|c|c|c|c|}
\hline & ig-Loss & $\mathrm{SiO}_{2}$ & $\mathrm{Al}_{2} \mathrm{O}_{3}$ & $\mathrm{Fe}_{2} \mathrm{O}_{3}$ & $\mathrm{CaO}$ & $\mathrm{MgO}$ & $\mathrm{Na}_{2} \mathrm{O}$ & $\mathrm{K}_{2} \mathrm{O}$ & $\mathrm{TiO}_{2}$ & $\mathrm{P}_{2} \mathrm{O}_{5}$ & $\mathrm{MnO}$ & $\mathrm{C}$ & $\mathrm{S}$ & Total \\
\hline FA & 1.05 & 24.73 & 10.33 & 4.95 & 38.35 & 4.54 & 4.03 & 0.84 & 0.51 & 0.13 & 0.00 & 0.32 & 10.15 & 99.94 \\
\hline
\end{tabular}




\subsection{Carbonation as a function of solid contents of suspension}

After selecting a solid-liquid rato capable of sufficiently agitating $\mathrm{CO}_{2}$ by implementing the above experiments, an experiment was conducted to check for reaction rates at which $\mathrm{CaO}$ component is transformed to a crystalline phase of $\mathrm{CaCO}_{3}$ by being combined with $\mathrm{CO}_{2}$. Also, to affirm the carbonation reaction behavior of fluidized bed fly ash, experiments were conducted while increasing the solid contents by preparing a suspension with $\mathrm{Ca}(\mathrm{OH})_{2}$ as the raw material so that $\mathrm{CaO}$ component excluding the components obstructed by various different components included in the raw material could be transformed to a crystalline phase of $\mathrm{CaCO}_{3}$. Carbonation experiments were conducted by selecting 4 stages of solid content by $30 \mathrm{~g}$ as a unit so that the weights of $\mathrm{Ca}(\mathrm{OH})_{2}$ were $30 \sim 120 \mathrm{~g}$, and by setting 4 levels for liquid content to obtain $300 \sim 1200 \mathrm{~g}$ for a slid-liquid ratio of $1: 10$ where the liquid content was the same as that of fluidized bed fly ash. To check how the carbonation reaction proceeded as a function of contents of the $\mathrm{CaO}$ component, carbonation reaction rates of the fluidized bed fly ash and those of $\mathrm{Ca}(\mathrm{OH})_{2}$ suspension were compared and analyzed. As the data to check for reaction rates of carbonation, neutralization reaction of $\mathrm{OH}^{-}$ions produced upon hydration of $\mathrm{CaO}$ was checked for by using a $\mathrm{pH}$ meter. For the data to check for reaction rates, a $\mathrm{pH}$ meter and a thermometer were used.

\section{Results and Discussion}

\subsection{Discussion on physical and chemical properties of fluidized bed fly ash}

The fluidized bed fly ash has been collected by a dust collector, and can be seen not to comply with the criteria for $\mathrm{F}$ class fluidized bed fly ash $\left(\mathrm{SiO}_{2}+\mathrm{Al}_{2} \mathrm{O}_{3}+\mathrm{Fe}_{2} \mathrm{O}_{3} \geq 70 \mathrm{wt} \%\right)$ and C-class fluidized bed fly $\mathrm{ash}\left(\mathrm{SiO}_{2}+\mathrm{Al}_{2} \mathrm{O}_{3}+\mathrm{Fe}_{2} \mathrm{O}_{3} \geq 50 \mathrm{wt} \%\right)$ per American Standard for Testing Materials specification (ASTM C 618), nor with KS specification (KS L 5405, $\mathrm{SiO}_{2} \geq 45 \mathrm{wt} \%$ ). This is considered attributable to the fact that the excess lime component failing to participate in desulfurization reaction remains in the fluidized bed fly ash by a large amount to make the relative contents of $\mathrm{SiO}_{2}$, $\mathrm{Al}_{2} \mathrm{O}_{3}, \mathrm{Fe}_{2} \mathrm{O}_{3}$ lowered. In the DTA/TG analysis (Fig. 1) of fly ash that was carbonated to examine Free-CaO contents capable of storing $\mathrm{CO}_{2}$, a great endothermic reaction near about $730^{\circ} \mathrm{C}$ and approximately $18 \%$ of weight loss are observed, which is a reaction where $\mathrm{CO}_{2}$, is decomposed from $\mathrm{CaCO}_{3}$, and the content of Free-CaO at this time is approximately $22 \%$ according to a calculation, indicating that approximately $22 \%$ of Free-CaO is present in the fluidized bed fly ash. ${ }^{10)}$ In addition, it was checked through XRD analysis (Fig. 2) whether carbonation did proceed in the carbonation process, and peaks of $\mathrm{CaO}$ component as the major crystalline phase were observed to correspond to a $\mathrm{CaCO}_{3}$ phase as crystals of the carbonated fluidized bed fly ash.
3.2. Carbonation experiment of fluidized bed fly ash

$\mathrm{CaO}$ component present in the fluidized bed fly ash is hydrated within the suspension to become $\mathrm{Ca}(\mathrm{OH})_{2}$ and subsequently ionized into $\mathrm{Ca}^{2+}$ ions and $\mathrm{OH}^{-}$ions by dissociation so as to increase $\mathrm{pH}$ of the solution due to $\mathrm{OH}^{-}$ions as well as to supply $\mathrm{Ca}^{2+}$ into the solution (the reaction (II) in Fig. 3) ${ }^{11,12)}$, where $\mathrm{Ca}(\mathrm{OH})_{2}$ exhibits a range of $\mathrm{pH} 12 \sim 13$ depending on temperatures because of the limited solubility in water. When $\mathrm{CO}_{2}$ gas is injected, it is hydrated to $\mathrm{H}_{2} \mathrm{CO}_{3}$, and then ionized into $\mathrm{H}^{+}$ions and $\mathrm{CO}_{3}{ }^{-2}$ ions by dissociation (the reaction (II) in Fig. 3), where $\mathrm{H}^{+}$ions are consumed by reaction with $\mathrm{OH}^{-}$ions to lower the $\mathrm{pH}$ values, and precipitates of $\mathrm{CaCO}_{3}$ are produced by reaction between $\mathrm{Ca}^{2+}$ ions and $\mathrm{CO}_{3}{ }^{2-}$ ions (the reaction (III) in Fig. 3), while weak acidity to neutrality at $\mathrm{pH} 6 \sim 7$ is exhibited after the reaction is finished.

According to Bauer et al., ${ }^{11)}$ diffusion distances within the aqueous solution was stated to control the carbonation reaction, and hence the carbonation reaction was considered to occur slowly due to insufficient diffusion distances if the solid-liquid ratio was small, i. e., the content of liquid in the aqueous solution ratio was small.

Figure 4 is a graph showing carbonation reactions as a

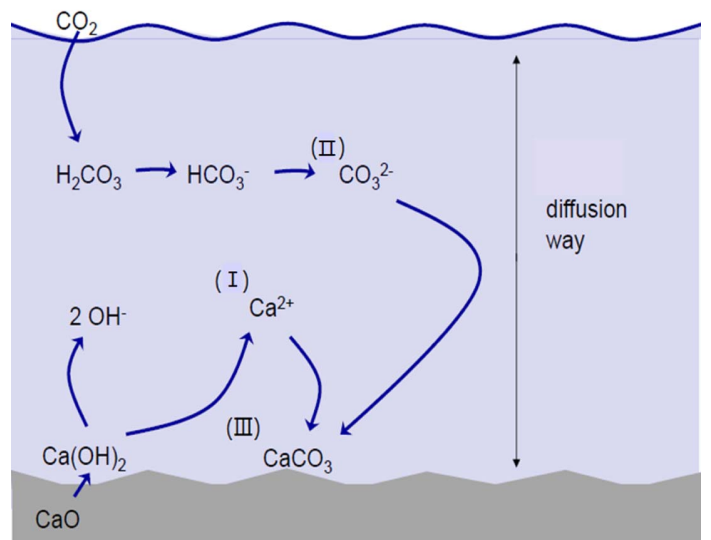

Fig. 3. Schematic process of carbonation in water.

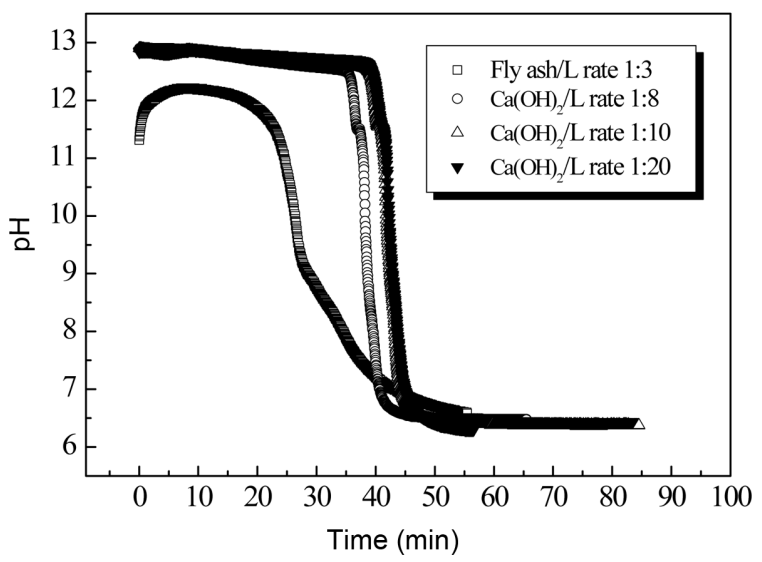

Fig. 4. $\mathrm{pH}$ variation of reacted solution during each solid: Liquid ratio with carbonation of fly ash and $\mathrm{Ca}(\mathrm{OH})_{2}$ 
function of solid contents under the condition where $\mathrm{CO}_{2}$ can be sufficiently transformed into an ionic state in the suspension. According to the results of observing carbonation reaction when liquid contents were changed under the experimental conditions where $\mathrm{Ca}(\mathrm{OH})_{2}$ was fixed at $30 \mathrm{~g}$ (based on the content of $\mathrm{CaO}$ component included in $100 \mathrm{~g}$ of fluidized bed fly ash), and the solid-liquid ratio (liquid content) made to be $1: 8(240 \mathrm{~g}), 1: 10(300 \mathrm{~g}), 1: 20(400 \mathrm{~g})$ for sufficient agitation of the suspension, neutralization of $\mathrm{pH}$ was observed to be completed in nearly the same time, in view of which a sufficient diffusion distance(liquid content) is considered to be secured if the ratio exceeds $1: 10$, and carbonation reaction at the solid-liquid ratio of $1: 3$ was affirmed to be in agreement when converted to the fluidized bed fly ash.

\subsection{Comparative carbonation experiment between} fluidized bed fly ash and $\mathrm{Ca}(\mathrm{OH})_{2}$

Carbonation was conducted by preparing a suspension with the solid-liquid ratio of $\mathrm{Ca}(\mathrm{OH})_{2}$ and water being fixed at 1 : 10 for the suspension, the $\mathrm{CO}_{2}$ flux at $700 \mathrm{cc} / \mathrm{min}$, and solid contents of fluidized bed fly ash to be $30 \sim 120 \mathrm{~g}$ in 4 stages by $30 \mathrm{~g}$ as a unit. Fig. 5 represents $\mathrm{pH}$ data according to carbonation experiment results per solid content of fluidized bed fly ash, while Fig. 6 shows a graph of temperature changes due to calorific values produced in the carbonation process. When the solid content of fluidized bed fly ash resulting from carbonation is $30 \mathrm{~g}$, completion time for carbonation reaction rate (time that $\mathrm{pH}$ shows neutrality after $\mathrm{OH}^{-}$ions of $\mathrm{CaO}$ are removed with conversion to $\mathrm{CaCO}_{3}$ ) is approximately 60 minutes, while it is 120 minutes for $60 \mathrm{~g}$, 180 minutes for 90 minutes, and 240 minutes for $120 \mathrm{~g}$, allowing affirmation of the fact that the times for completion of the reaction rates are linearly increased as the solid contents are increased in this way. When weight changes of $\mathrm{Ca}(\mathrm{OH})_{2}$ in Table 2 are checked, it can be seen that carbonation of nearly all raw material has been realized in view that the rates of weight change in excess of $90 \%$ compared with theoretical values are observed. Since this is a nonuniform reaction like a decarboxylation process of the equation (1) presented by Kingery et al., ${ }^{13)}$ carbonation process would occur at the reaction interface so that the reaction rates

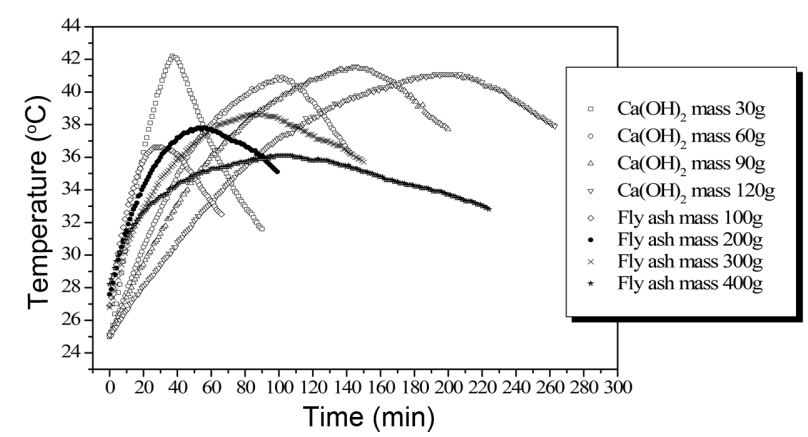

Fig. 5. $\mathrm{pH}$ variation of carbonation reaction with the quantities of $\mathrm{Ca}(\mathrm{OH})_{2}$ and fly ash. were expected to be proportional to the $1 / 2$ power of time. However, the experimental results showed a linear increase.

$$
(1-\alpha)^{1 / 2}=1-k t / r_{0}^{13)}
$$

where $\alpha=$ decomposition efficiency

$k=$ rate constant of reaction

$t=$ time

$r_{0}=$ initial particle radius

Whereas the decarboxylation reaction occurred in a gaseous phase where diffusion as matter movement was not the rate-controlling reaction and was an interface reaction which was proportional to the $1 / 2$ power of time, the present experiment is realized in water where diffusion or matter movement becomes the rate-controlling reaction, and not only solubilities of $\mathrm{Ca}^{2+}$ ions and $\mathrm{CO}_{3}{ }^{2-}$ ions in water are increased, but also water temperatures are increased at the same time due to the exothermic reaction as the reaction of (III) occurs while the reactions of (I) and (II) in Fig. 3 are endothermic reactions. These are considered to result in increased reaction rates so as to exhibit linear reaction rates. This can be explained by the fact that $\mathrm{pH}$ of the suspension in Fig. 5 is drastically reduced from the point of showing the maximum temperature in reaction temperatures of Fig. 6. ${ }^{8,12)}$ Subsequently, when compared with the carbonation process of fluidized bed fly ash, it could be affirmed that the end times were nearly the same although reaction start time occurred first in the case of fluidized bed

Table 2. Weight Change after Carbonation with $\mathrm{Ca}(\mathrm{OH})_{2}$

\begin{tabular}{cccc}
\hline \multirow{2}{*}{$\mathrm{Ca}(\mathrm{OH})_{2}$} & \multicolumn{3}{c}{ After Carbonation $\left(\mathrm{CaCO}_{3}\right)$} \\
\cline { 2 - 4 } & $\begin{array}{c}\text { theoretical } \\
\text { weight(A) }\end{array}$ & $\begin{array}{c}\text { experimental } \\
\text { weight(B) }\end{array}$ & $\begin{array}{c}\mathrm{B} / \mathrm{A} * 100 \\
(\%)\end{array}$ \\
\hline $30 \mathrm{~g}$ & $40 \mathrm{~g}$ & $40 \mathrm{~g}$ & $100 \%$ \\
$60 \mathrm{~g}$ & $81 \mathrm{~g}$ & $79 \mathrm{~g}$ & $90 \%$ \\
$90 \mathrm{~g}$ & $121 \mathrm{~g}$ & $120 \mathrm{~g}$ & $96 \%$ \\
$120 \mathrm{~g}$ & $162 \mathrm{~g}$ & $160 \mathrm{~g}$ & $95 \%$ \\
\hline
\end{tabular}

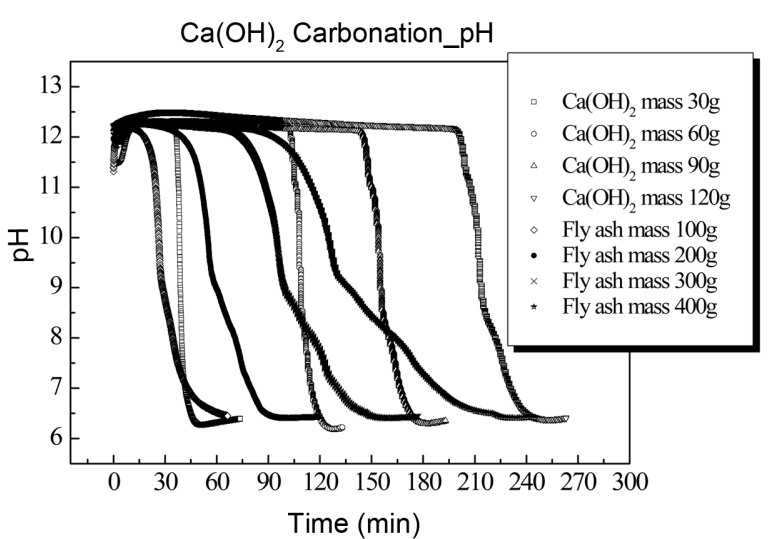

Fig. 6. Temperature variation of carbonation reaction with the quantities of $\mathrm{Ca}(\mathrm{OH})_{2}$ and Fly ash. 
fly ash, thus allowing affirmation of the fact that carbonation behavior of the fluidized bed fly ash depended on the content of Free-CaO. Also, considering reaction rates of the fluidized bed fly ash, gradual drop from the point where carbonation starts can be affirmed, which is considered to be caused by obstruction of diffusion of $\mathrm{CO}_{3}{ }^{2-}$ ions due to the components not contributing to carbonation in the composition of fluidized bed fly ash(Fig. 3). According to the results of implementing an experiment where solid content and liquid content were selected according to the content of $\mathrm{CaO}$ component and made to be identical, times for completion of carbonation can be seen to be in agreement. Based on this, the rates of carbonation can be expected to increase linearly with the content of $\mathrm{CaO}$ contained in the fluidized bed fly ash.

\section{Conclusion}

Carbonation reaction of fluidized bed fly ash was in accurate agreement with that of $\mathrm{Ca}(\mathrm{OH})_{2}$, and hence $\mathrm{Ca}(\mathrm{OH})_{2}$ is considered to be carbonated by hydration reaction of Free$\mathrm{CaO}$ contained in the raw material.

Although carbonation reaction of the fluidized bed fly ash is a nonuniform reaction where the reaction occurs at the interface, and hence the reaction rates were predicted to be proportional to the $1 / 2$ power of time, the increase was observed to be linear according to the experimental results. Whereas the decarboxylation reaction was realized in a gaseous phase where diffusion or matter movement was not the rate-controlling reaction but an interface reaction proportional to the $1 / 2$ power of time, the present experiments are realized in water so that diffusion or matter movement becomes the rate-controlling reaction. Considering carbonation behavior of $\mathrm{Ca}(\mathrm{OH})_{2}$, while dissolution reaction of $\mathrm{Ca}^{2+}$ ions of $\mathrm{Ca}(\mathrm{OH})_{2}$ together with ionization reaction of $\mathrm{CO}_{2}$ gas in water are endothermic reactions, $\mathrm{Ca}^{2+}$ ions and $\mathrm{CO}_{3}{ }^{2-}$ ions dissolved in water are expected to become $\mathrm{CaCO}_{3}$ by exothermic reaction, thus increasing reaction rates so as to exhibit linear reaction rates.

Through this, rates of carbonation reaction of the carbonstoring fluidized bed fly ash with $\mathrm{CaO}$ component contained were checked, and the reaction rates and the behavior could be predicted by using wet carbonation for the experiment as a function of the contents of $\mathrm{CaO}$ component. Based on this, advantages of being able to recycle the wastes could be seen by storing $\mathrm{CO}_{2}$ in the fluidized fly ash which contains a large amount of $\mathrm{CaO}$ component as a waste produced at thermal power plants.

\section{REFERENCES}

1. N. S. Ahn, J. H. Lee, and Y. H. Lee, "Sulfate Attack According to the Quantity of Composition of Cement and Mineral Admixtures," J. Korea Inst. Build. Constr., 11 [6] 547-56 (2011).

2. K. H. Kim, J. Y. Lim, D. H. Ryu, and S. W. Choi, "The Present Situation of Production and It's Utilization of Electronic arc Furnace Oxidizing Slag in Korea and Other Countries," J. Korea Concr. Inst., 19 [6] 51-57 (2007).

3. T. B. Byeon, J. Y. Lee, D. Y. Kim, H. H. Lee, and H. S. Kim., "Carbonation Treatment Technology of Steel Making Slag," Rist. J. R\&D, 19 [1] 32-39 (2005).

4. J. W. Ahn, H. S. Kim, J. S. Cho, G. C. Han, K. S. Han, and H. Kim, "Manufacture of Ordinary Portland Cemnet Clinker Using Cement Paste of the Waste Concrete(in Korean)," J. Korean Ceram. Soc., 40 [8] 804-10(2003)

5. H. S. Kim, K. H. Han, and W. H. Bae, "Method for Stabilizing Steel-Making Slag by Adding Iron-Containing Material with High T-Fe Content," Republic of Korea Patent, Patent No. 10-0538586 (2005).

6. H. S. Kim, K. H. Han, and W. H. Bae, "Method for Producing Concrete Using Steel Slag Aggregate that Quickly Blocks Expansion of Steel Slag Aggregate by Adding Water Glass," Republic of Korea Patent, Patent No. 10-0592870 (2006).

7. K. G. Lee, J. S. Kim, Y. T. Kim, and S. K. Kang, "Carbonization of Coal-Fly Ash Containing High CaO Compound(in Korean)," J. Korean Ceram. Soc., 50 [1] 18-24 (2013).

8. J. W. Ahn, J. W. Park, J. S. Kim, and C. Han, "A Study on Characteristics of Precipitated Calcium Carbonate Prepared by the Nozzle Spoting Method," J. Korean Ind. Eng. Chem., 17 [1] 67-72 (2006).

9. H. Y. Jo, J. H. Kim, Y. J. Lee, M. h. Lee, and S. J. Choh, "Evaluation of Factors Affecting Mineral Carbonation of $\mathrm{CO}_{2}$ Using Coal Fly Ash in Aqueous Solutions Under Ambient Conditions," Chem. Eng. J., 183 77-87 (2012).

10. J. S. Sim, K. G. Lee, Y. T. Kim, and S. K. Kang, "Hydration Characteristics of Coal-Fly Ash Containing High $\mathrm{CaO}$ Compound(in Korean)," J. Korean Ceram. Soc., 49 [2] 18590 (2012)

11. M. Bauer and N. Gassen, $\mathrm{CO}_{2}$ Binding of Various Alkaline Residues: Experiments in the Laboratory Eirich Mixer at Semi-dry Conditions; pp. 12, Report, Department of Hydrology, University of Bayreuth, 2010.

12. J. W. Hwang, Y. Lee, and D. H. Lee, "Morphological Change of Precipitated Calcium Carbonate by Reaction Rate in Bubble Column Reactor," Korean Chem. Eng. Res., 47 [6] 727-33 (2009).

13. W. D. Kingery, D. R. Uhlmann, and H. K. Bowen, Introduction to Ceramics; pp. 485-504, BANDO Publisher, Korea, 1995. 